\title{
The Locations of (World) Literature: Perspectives from Africa and South Asia
}

\section{Introduction}

\author{
Francesca Orsini \\ soAs University of London \\ fo@soas.ac.uk
}

\section{Laetitia Zecchini}

Centre national de la recherche scientifique

laetitia.zecchini@cnrs.fr

to a poem, the location, whether cultural, historical, geographical or fictive - is everything.

MEHROTRA 168

That location matters for critics, readers but also texts, as Arvind Krishna Mehrotra's quote suggests, is a deceptively simple point. To some readers, location as context and standpoint reveals and deepens a text's possibilities, to other readers it constricts and confines them. Indeed, the apparent paradox of locatedness and open-endedness is at the heart of many writerly and critical reflections on location and literature, as is the idea that literature both inhabits and creates worlds.

There is no escape from the location of perspective or point of view, be it one or many. This is all the more crucial in world literature, which attempts to view and connect literary phenomena on a very large scale. "For any given observer," David Damrosch argued in What is World Literature?, "even a genuinely global perspective remains a perspective from somewhere, and global patterns of the circulation of world literature take shape in their local manifestations" (27). Yet 
in world-system or field theories, and in approaches that focus on "global" circulation, this important insight gets sidelined or forgotten. Applied to literature, world-system and field theories produce a limited range of possible and alternative positions, as if dealing the players a very small pack of cards: subjection or revolt, emulation or appropriation, marginality or cosmopolitanism, indigeneity or foreignness. To turn to another, visual, metaphor, writers, publishers, editors, critics, translators working in the putative centres on the world literary map are implicitly endowed with a better or wider field of vision, as if they were standing on a hill. They can recognize literary value and bestow recognition, and they are implicitly more "universal," worldly or innovative than their counterparts in the so-called literary peripheries. Compare with the proliferation and instability of location in Gujarati painter and writer Gulammohammed Sheikh's formulation (from Zecchini's contribution to this volume):

The multiplicity and simultaneity of these worlds filled me with a sense of being part of them all. Attempts to define the experience in singular terms have left me uneasy and restless. It was a multiverse of sorts. And I decided to use it all.

Location, then, for us is not simply a geographical, historical, or cultural context but a standpoint, a position, an orientation, a necessarily partial and particular perspective, however complex, ample and multiversal it may be, from which a writer represents and imagines his or her worlds.

However, the constraint of location in the form of a geographical tag or label has been felt perhaps most acutely by Asian and African writers, wherever they may actually live. ${ }^{1}$ For this reason, we wanted to explore how modern and contemporary South Asian and African writers who produce their work from specific locales consider their place in the world, in world literature, and in the wider geographical regions (Africa, South Asia, Maghreb, etc.) or national literary histories that their work is often read in or identified with. How do these writers work through, use, challenge or re-invent the macro categories (region, nation, sub-continent, continent, world) with which literary histories are written and literary cartographies are constituted? What is the relevance of these geographical categories to them, and how do they reallocate or realign them? What worlds do these literatures simultaneously inhabit and create? What networks - often transnational or multilingual, but rendered invisible

1 A constraint which some critics have even considered a "curse." See Chakrabarty on the "curse of belatedness" which, he says, has never been completely lifted from India (163). 
or underground in singular views of the world literary space - do writers and institutions, specific genres and works of literature, but also circuits of readership, translation and publishing, produce? And what are the imagined, alternative, or discrepant geographies, the different cosmopolitanisms, that may be invented in the process?

Location is therefore a useful prism through which to explore, from the perspectives of authors and materials from multilingual South Asia, Africa, and the Maghreb, issues at the centre of world literary studies today and to probe some implicit assumptions. Our hope is that this ground-up approach - from Lagos, Algier, Niamey, Addis Ababa, Allahabad, Dar es Salam, or Bombay/Mumbai; in English and in French but also in Swahili, Malayalam, Amharic, Urdu, Arabic, Persian, or Pulaar - can pluralize a map whose traffics, entanglements, complexities, but also discontinuities and asymmetries, face the risk of being ironed out by reified conceptualizations of literature within global macro-systems. The central issues examined in the eleven essays of this two-part special issue include visibility and invisibility (or invisibilisation), circulation, worlding or being-in-the-world, multilingualism, and scale. Let us take them one by one.

\section{$1 \quad$ Visibility and Invisibility}

Making parts of the world, literary and non-literary, visible or invisible is surely one of the main effects of world literature. Visibility means recognition; it may indicate a special attention and curiosity, admiration, or solidarity. Earlytwentieth century Indian periodicals in English, Hindi, and Urdu made Asian literatures visible as part of a newly-found sense of anti-colonial solidarity, and relativized the centrality of English vis-à-vis other European literatures (Orsini in this issue). By contrast, African and Latin American literatures only became visible to Indian readers in the 1950 os and 196os. Conversely, the invisibilisation of modern Indian literatures and writers by orientalist scholars and critics in Europe in the nineteenth century played into assumptions about the backwardness and/or decay of an India only revived by British colonialism (see Orsini "Present Absence"). Nowadays festivals, Claire Ducournau shows in these pages, are a prime "site" in which "African literature" is made visible, performed, discussed, but also challenged and partly invisibilised. For one thing, "considered in their materiality and as dynamic sites of meaning creation," these events which have spread inside and outside Africa "privilege a 'continental' representation of culture, which involves a de-nationalization of Africa (and a de-nationalization of literature)," Ducournau argues. This "often reveals itself as problematic when confronted with the complex geographies of 
the texts and authors represented at these festivals." Festivals thus also become sites of intense negotiation and contestation - between writers living locally and diasporic ones, between Afrophone and Francophone, and so on. The oppositions work at multiple levels, with diasporic or nomadic Francophone writers contesting the hegemony of Paris being in turn contested by local Francophone and Afrophone writers. Ducournau's ethnographic approach shows that such identifications, polarities and oppositions become effective during festivals like the "Étonnant Voyageurs" festival in Saint-Malo and its relocated version in Bamako, of which the "manifeste pour une littérature-monde" was a product: "One advantage of the ethnographic approach is that it keeps these tensions alive and embodies these otherwise static identities in concrete and relational ways of being."

We also tend to think of world literature as expressing a longing for visibility. And yet there are many instances of writers who cultivated invisibility and anonymity, who chose to remain "missing persons," and whose eccentricity or marginality precisely accounts for their worldliness and their creativity (see Zecchini “Translation”). Mélanie Bourlet's essay on Pulaar literature offers a striking example of great worldliness, connectivity, and value coupled with almost complete invisibility:

The first difficulty inherent in literatures that are little institutionalized is their near invisibility in places where we are accustomed to look for books: bookstores, libraries and, nowadays, bookselling websites that make it possible to order books from far away. By contrast, research such as this must begin practically by chance and continue by following scant traces. These literatures invite us to venture off well the beaten tracks of official book circuits, and to follow other routes revealed by the encounters with those who enable their existence.

The lengthy journeys across continents that Bourlet had to undertake to gain access to the books - which were precious in the eyes of their keepers - made them precious also in her eyes and "radically changed [her] relationship to literature." Instead of books looking for readers in a market dominated by supply, here we have readers looking for books in limited supply, and the researcher having to integrate a transnational network of Pulaar community activists in order to gain access to them. Yet relative invisibility and precariousness do not mean isolation, or withdrawal from linguistic, political and social forces. Rather, "Through the mobility and instability that characterize these activist spaces, this literature claims the possibility to exist anywhere in the world - to appear, disappear, and reappear anywhere, without territorial limits. Its exis- 
tence does not depend on government institutions but on local and transnational solidarities. In this sense, it thwarts the institutionalized literary geography which World Literature presents as the dominant pattern."

Circulation in world literature is usually understood as happening through translation and/or publishing conglomerates, particularly in the case of Anglophone literature or literature "born translated" (Walkowitz), i.e. written with translation already in mind or featuring literal or figurative self-translation. Yet translation features prominently only in a few of the essays of this two-part special issue (Burney, Leperlier, McDonald, and Zecchini). Partly this is because certain language fields - like Arabic - are transregional and transnational already, without translation (Laachir). Partly it's a question of the medium of circulation: in the "cut-and-paste" Indian magazines of Orsini's essay, world literature circulated less as translation and more as review, name-dropping, or brief introduction. This produced only a "thin description" of distant authors and works and no direct "readerly encounter" (Thornber). However, even that sprinkling of names and collage of news engendered in readers a kind of familiarity which, she argues, should not be underestimated, and which is after all a very common experience of world literature (as answers to "which famous authors haven't you read?" always reveal).

Moreover, Orsini's and Fatima Burney's essays show that relay translation, re-translation, and even pseudo-translation have perhaps been more the norm in world literature than we tend to assume, and require their own critical attention and recognition. The curious reframing of Hafez as the "Persian bard" and of Persian ghazal poetry (a genre especially recalcitrant to localizing interpretations) as Naturpoesie or folk poetry that accompanied the "arrival" of Hafez's ghazal poetry into world literature through R.W. Emerson, Burney argues, should not be dismissed as a conceptual mistranslation. It is rather an index of the worldliness and the "flexibility that the conventionalized and highly metaphoric language of the ghazal offers."

Circulation directs attention not only to the specificity of medium - magazine vs anthology, chapbook vs series of classics -, but also to the tension between book and text. It also highlights the role played by the various intermediaries behind the scene, the "interconnected world of authors, translators, publishers, printers, warehouses, ships, agents, booksellers and readers," best explored in Peter McDonald's essay. As Roger Chartier has put it, readers "never confront abstract, idealized texts detached from any materiality" (qtd. 
in McDonald). Using the different editions and translations of J.M. Coetzee's In the Heart of Country as a test case, McDonald directs our attention to the "fallible artefact of writing" that a work of literature represents. Encountering the world via literature is "about the way we experience the ongoing creative potential of each individual work," constantly reactivated by the resources of each new language and writing system, the unique intercultural and interlingual connections that a new work and a new translation open up.

The essays of this special issue make two further points about circulation. First, Bourlet, Ducournau, Orsini, and Zecchini stress the fact that even though rhetorically institutions of world literature, from festivals and writers' organizations to magazines, emphasise the systemic quality of circulation, in reality the networks that sustain it are more fragile, informal, and serendipitous. This inevitably results in greater visibility for the authors at hand and invisibilisation for the others. The lesson here is that we have to be cautious of rhetorical claims about the systematic and global nature of world literature, what Aamir Mufti calls "varieties of one-world thinking - diverse perspectives ... that all nevertheless require imagining the world as a continuous and traversable space" (5).

For more established circuits, certain "technologies of recognition" (Shih) recur. In the case of multilingual Maghreb, both Karima Laachir and Tristan Leperlier show that Arabic and French have their own "significant geographies" (Laachir, Marzagora \& Orsini) that respectively connect Arabic writers to publishers, writers, readers and critics in the Mashreq ("the east," i.e. Egypt, Lebanon, and Syria), and Francophone writers to publishers, writers, readers and critics in France. The two are interrelated - so that recognition (and translation) in France results in circulation and recognition in Arabic in the Mashreq. At the same time, as Leperlier puts it in the second part of this special issue ( $J W L 4.2$, forthcoming), "The bilingual and transnational Algerian literary field requires different levels of interconnected analysis - of the two linguistic subfields, the national literary field, and the two Francophone and Arabophone transnational literary fields. This multiplicity of levels allows us to carefully examine local practices without forgetting that they are entangled in global hierarchies of legitimacy." Yet both authors show that local (or national) and transregional pressures, needs, and contexts may be more significant than global hierarchies of legitimacy for understanding specific aesthetic and narrative choices.

Finally, we also need to bear in mind the writers' own perspectives on these circulations. Some of the writers and artists in Laetitia Zecchini's essay, for example, viewed themselves as "indiscriminate literary gluttons, ragpickers, pirates, or 'poachers' in Michel de Certeau's sense of the term." So what we have is a delight in "world literature" not as an exclusive circle of literary mas- 
terpieces or "born-translated" novels, but as the "indiscriminate, non-canonical and non-hierarchical material (including material from popular and public culture) to poach, excerpt, steal, assemble, 'ingurgitate,' play with, recycle, and make one's own."

\section{Being-in-the-World, Worlding}

Several of the essays in this collection, and we as editors, share the wariness about positivist notions of the world that is expressed most forcefully in Sara Marzagora's essay, where she makes the case for an "existential phenomenology's account of the-person-in-the-world" (Doyle qtd. in Marzagora). We share Pheng Cheah's understanding of world literature as "both a site of processes of worlding and an agent that participates and intervenes in these processes" (2). In this perspective, as Marzagora shows in her essay on the Ethiopian Amharic writer Käbbädä Mikael, location becomes an orientation which produces affiliations that shift with historical, political, and personal circumstances: Käbbädä's acts of worlding through his writings shifted from Europe, to Japan, to Africa. In the case of India, as Laetitia Zecchini's essay shows, this "opening up and out into" (to use Xavier Garnier's formulation) is directed simultaneously at Indian and world literatures, and the same writers, associations, and magazines that actively seek to inform about and translate from foreign literatures are typically also those that do the same with literatures in other Indian languages.

One important aspect of this re-orientation is that it draws attention to other meanings and resonances of "world" in the various languages and conceptual vocabularies. Thus Burney notes that, "In Urdu poetry and particularly ghazal poetry, dunyā, which is the word most commonly used to mean 'world,' often carries a connotation of lack; it is something which is simply worldly rather than eternal, like the divine ... Accordingly, to be fully concerned with the world is to have lost sight of the ultimate and eternal truth(s) which go beyond the physical realm of perception." For Rabindranath Tagore, McDonald argues, vishva ("world"), carried resonances of the bhakti devotional poets, who said:

I have made the world my home

And my home the world.

I have made "others" my own people,

And my own people "others".

CHANDIDAS trans. OPENSHAW vi 
For Tagore, literature constitutes "'a world' (ektijagat), the creative potential of which is, 'like the material world,' always 'ongoing' and 'incomplete'" (Tagore Rabindra $77^{2}$ qtd. in McDonald). And it belongs to the realm of ananda ("joy" or "delight") which "connects it to a wide range of other seemingly gratuitous or superfluous everyday activities" (McDonald) and is "a movement of affect which binds human beings together" (Chaudhuri 85 qtd. in McDonald). To be attuned to these resonances is crucial to understand the significance and specificity of these "worlding" utterances without flattening them on the plane of instant translatability and transparency, or the language of "pure meanings" to use McDonald's expression.

Location as "being in the world" and orientation refers not just to persons (Marzagora) and groups (Bourlet) but is relevant also for languages - as in Wittgenstein's "picture theory" - and for genres. Thus Xavier Garnier points out that the "Kiswahili language itself inscribes the diversity of the world through a lexicon that retains the memory of its various origins in numerous Bantu, Persian, Arabic, and European languages" - "retains the memory" is the key term here, for of course this would partly be true of every language. Modern Swahili literature, as Garnier suggests in his discussion of the crime novel from the '6os onwards, and later on the ethnographic novel, is "extrovert," and even local plots are shot through with foreign entanglements, though the attitudes towards the outside world, which is increasingly perceived as threatening, have changed.

One of the most exciting and creative ways in which contributors to this special issue have approached the notion of location in world literature has been through genre. Each genre, as we know, codifies a particular relationship between signifier and signified and thus establishes its own, recognizable idiom and rhetoric. But while each genre carves up the world and limits the universe of discourse according to its partial intention, it presents itself to the reader or listener as a whole (Conte). Therefore to decode the location and perspective of a genre to the world - often in relation to other genres and discourses - is a rewarding exercise. We have already mentioned the magazine itself as a genre as well as a repository of genres. The intertextual fabric of a monthly such as The Indian PEN in the 1930s, '4OS and '5os (Zecchini), like the Modern Review (see Orsini's contribution), provides a "cut-and-paste collation of the world" and of world literature which was also a means for Indian writers to claim a space on the world literary stage, and assert their significance on a par with other nations and other literatures. Soofia Siddique's essay takes up worlding from the perspective of a nineteenth-century Urdu advice book for children, Nazir Ahmad's classic Chand Pand (Some Lessons) and situates it at the crossroads between the much older tradition of Islamicate ethical books, 
which had their own "significant geographies," the new world of the colonial geography lesson, old and new ideas of travel, and the specific quality of (local) places. The evocation of what local places are famous for "defies a synecdochal relationship with the global, and the whole is not to be derived seamlessly from the parts." Instead, Siddique draws upon Arif Dirlik's "place-based thinking or imagination" to argue that "Nazir Ahmad's extended paean to individual towns," some of which were fading at the time he wrote, "emerges as a lyrical claim staked for the particularity of places." This claim in Nazir Ahmad's narrative of the world, "resists the threat of the theoretical denial of 'place' by its transmutation into the abstraction of empty space" (Siddique).

In his essay, Xavier Garnier shows how Shabaan Robert used the classical epic genre of utenzi to draft his epic work (300o stanzas) and narrate the story of World War II, in effect locating the world in Swahili, and for an African audience. The ghazal's dismissal of dunya ( "the world," this world) has already been remarked on. As Burney notes, classical ghazals have little to say about location or their locatedness, given that "their poetic practice is primarily concerned with recasting and refining established poetic principles rather than representing reality." In fact, she notes, "the classical ghazal - and particularly styles that privileged ambiguity (ihām-go' $\bar{\imath}$ ) and word play - was actually more interested in articulating dislocation," and "the extreme power imbalance between the ghazal's protagonist (the lover or 'āshiq) and his beloved is regularly versified as separation (hijr) from the beloved or as alienation ( $\dot{g}$ hurbat)." Her essay deals with the substantial recasting of this being-in-the-world of the ghazal by critics both in Europe and in India wedded to very different ideas of poetry and nature, in which location and locatedness were central.

Karima Laachir's essay - and to some extent Tristan Leperlier's - show how Maghrebi novelists recast the older Arabic genre of the rihla or literature of travel. Laachir's essay focuses on one particular kind of rihla, the "westward journey" (taghrïba) of the Banu Hilal which, she shows, has been crucial to Arabic discourse and identity in the Maghreb, both in oral and written, local and pan-Arabic traditions. The novels she discusses by a Tunisian, Egyptian, and Moroccan novelist use familiar generic referents to the tagh their own specific critiques of their postcolonial regimes. "Location, these novels show, is rooted in national debates while being open to the shared transregional Arabic cultural and political space" (Laachir). Their "significant geographies" are imaginative (in Abdelrahim Lahbibi's novel), conceptual (Waciny Laredj's Algerian and pan-Arabic space) and/or real (Majid Toubia's remapping of Egyptian history). Furthermore, Leperlier shows how, in Tahar Djaout's, Rachid Boujedra's and Tahar Ouettar's novels, the familiar imaginary of the desert is recast to articulate the different dilemmas and alternatives that these 
three writers feel their society is trapped in, at a time when Islamists were imposing a very restrictive Arab-Muslim definition of Algerian identity.

\section{$4 \quad$ Against Fixity and Interpellation}

It is important to acknowledge that one aspect of the insistence on location and on the "interpellation" (Althusser) of writers as belonging to, and presumably fixed in, specific languages, places, or identities has been the vocal rejection of such imposition. Many of the essays in this special issue highlight the different ways by which African, South Asian or Maghrebi writers challenge the ethnicizing expectations thrust upon them by a global publishing market (see in particular Ducournau, Leperlier). Many also point to the unstable or provisional ground of location, the always multiple, unresolved and shifting geographies that works of literature inhabit, imagine and create. We already saw it with Tagore, who famously articulated his position on vishvasähitya in opposition to the new discipline of Comparative Literature, which he felt was chopping up the world and literature in unhelpful and dangerous ways. "We do not properly understand literature (sāhitya)," Tagore stressed "if we reduce it to place-time-thing (desh-kāl-pātra)" (Tagore qtd. in McDonald).

A similar spirit of reaction animates some of the poets in Laetitia Zecchini's essay, who understand location, following James Clifford, as an "itinerary rather than a bounded site - a series of encounters and translations," and as history. If Arvind Krishna Mehrotra's poems are grounded in the "here" of immediate surroundings, this location is never a given. It is a place to connect and defamiliarize with a multiplicity of other places, other temporalities, other literatures, and occasionally other languages. Drawing on Amit Chaudhuri's insightful comment that Mehrotra's poetry foregrounds a view of literature as "space" rather than inheritance, Zecchini also shows that the world of these poets is a worldas-bricolage and a world-as-assemblage that is inseparable from the practice of reading and writing as poaching, by which the world and one's place in it are being constantly remade, and literature also becomes a "space" where "East" and "West" do not exist as prior, stable constructs but are constantly reallocated.

To end with a point that Karima Laachir makes in her contribution, when we take a located approach to the study of world literature as it circulates in national and transregional cultural spaces, a different picture of the world in "world literature" emerges: one that is no longer generic and global but is shaped by what we call "significant geographies," a formula that captures the complexity of the changing interaction between the local, the regional and the 
global, those "worldly, productive sites of crossing; complex, unfinished paths between local and global attachments" that James Clifford identifies with certain forms of cosmopolitanism (Clifford 362). By shifting the focus to specific voices, geographies and imaginaries, our aim has been to be attentive, following Sanjay Krishnan, to the "claims of contextual unevenness and heterogeneity" (1) that world literature should be so well placed to discover and highlight.

\section{Acknowledgements}

Most of the essays in this special issue were first presented during a conference organized at the École normale supérieure in Paris in June 2017. This conference received support from the labex TransferS (laboratoire d'excellence, program "Investissements d'avenir" ANR-1O-IDEX-OOO1-O2 PSL *and ANR-1O-LABXoog9) and the soAs "Multilingual Locals and Significant Geographies" project which received funding from the European Research Council (ERC) under the European Union's Horizon 2020 research and innovation programme (grant agreement No. 670876).

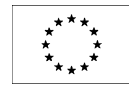

\section{Works Cited}

Althusser, Louis. Idéologie et appareils idéologiques d'État. Paris: Presses Universitaires de France, 2011.

Chakrabarty, Dipesh. "Belatedness as Possibility: Subaltern Histories Once Again." In The Indian Postcolonial. Eds. Elleke Boehmer and Rosinka Chaudhuri. Abingdon: Routledge, 2010, 163-76.

Chaudhuri, Supriya. "Singular Universals: Rabindranath Tagore on World Literature and Literature in the World." In The World as His Nest. Eds. Subhoranjan Das Gupta and Sangeeta Datta. Kolkata: Jadavpur UP, 2016, 74-88.

Cheah, Pheng. "What is a World? On World Literature as World-making Activity." Daedalus 137:3 (2008), 26-38.

Clifford, James. "Mixed Feelings." In Cosmopolitics: Thinking and Feeling Beyond the Nation. Eds. Pheng Cheah and Bruce Robbins. Minneapolis: University of Minnesota Press, 1998, 362-71.

Conte, Gian Biagio. Genres and Readers: Lucretius, Love Elegy, Pliny's Encyclopedia. Baltimore: Johns Hopkins UP, 1994. 
Damrosch, David. What is World Literature? Princeton: Princeton UP, 2003.

Krishnan, Sanjay. Reading the Global: Troubling Perspectives on the British Empire in Asia. New York: Columbia UP, 2007.

Laachir, Karima, Sara Marzagora, and Francesca Orsini. "Significant Geographies: In Lieu of World Literature." Journal of World Literature 3:3 (2018), 290-310.

Mehrotra, Arvind Krishna. Partial Recall: Essays on Literature and literary History. Delhi: Permanent Black, 2012.

Mufti, Aamir R. Forget English!: Orientalisms and World Literatures. Cambridge: Harvard UP, 2016.

Openshaw, Jeanne. Seeking the Bāuls of Bengal. Cambridge: Cambridge UP, 2002.

Orsini, Francesca. "Present Absence: Book Circulation, Indian Vernaculars and World Literature in the Nineteenth Century." Interventions [forthcoming].

Shih, Shu-Mei. "Global Literature and the Technologies of Recognition." PMLA 119:1 (2004), 16-3o.

Thornber, Karen L. Empire of Texts in Motion: Chinese, Korean, and Taiwanese Transculturations of Japanese Literature. Cambridge: Harvard UP, 2009.

Walkowitz, Rebecca. Born Translated: The Contemporary Novel in an Age of World Literature. New York: Columbia UP, 2015 .

Zecchini, Laetitia. "Translation as Literary Activism: On Invisibility and Exposure, Arun Kolatkar and the Little Magazine 'Conspiracy.' In Literary Activism: A Symposium. Ed. Amit Chaudhuri. Oxford: Oxford Up/Boiler House Press, 2017, 25-55. 